\title{
Preventing Sudden Cardiac Death during Marathons with Pre-Race Aspirin
}

\author{
Arthur J. Siegel1,2 \\ ${ }^{1}$ Internal Medicine, McLean Hospital, Belmont, USA \\ ${ }^{2}$ Harvard Medical School, Boston, USA \\ Email: asiegel@partners.org
}

Received 30 June 2015; accepted 22 August 2015; published 25 August 2015

Copyright (C) 2015 by author and Scientific Research Publishing Inc.

This work is licensed under the Creative Commons Attribution International License (CC BY). http://creativecommons.org/licenses/by/4.0/

(c) (i) Open Access

\section{Abstract}

Objectives: Prevention of sudden cardiac death is the number one clinical priority in sports cardiology. While the overall cardiovascular risk of long distance running is acknowledged as low, the frequency of cardiac arrests and sudden death has increased in middle-aged males during marathons since the year 2000. An evidence-based strategy for protecting susceptible runners from these acute cardiac events during races is considered based on identification of the underlying cause. Method: Review of articles in Pub Med on adverse cardiac events during marathons. Findings: Recent epidemiological studies have identified an increasing frequency of cardiac arrest in middle-aged males during marathons since the year $\mathbf{2 0 0 0}$ with atherosclerotic heart disease as the main cause of sudden cardiac death. Same-aged asymptomatic middle-aged male physician-runners showed a post-race polymorphonuclear leukocytosis with sequential increases in interleukin- 6 and C-reactive protein as a likely consequence of rhabdomyolysis after "hitting the wall". Increased fibrinogen, von Willebrand factor and D-dimer with in vivo platelet activation indicated a concurrent hemostatic imbalance with pro-coagulant effects. Cardiac troponins I and T and NT-pro-B-type natriuretic peptide were elevated after races as additionally predictive of acute cardiac events in asymptomatic persons. Conclusions: High short-term risk for acute cardiac events in asymptomatic middle-aged male runners is shown by stratification of validated biomarkers, which may render non-obstructive coronary atherosclerotic plaques vulnerable to rupture during marathons. Pre-race aspirin usage is prudent to reduce these events mediated by atherothrombosis based on conclusive evidence for prevention of first acute myocardial infarctions in same-aged healthy male physicians. Prospective studies are needed to determine the efficacy of pre-race low-dose aspirin for curtailing the increasing frequency of race-related cardiac arrest and sudden death in susceptible runners.

\section{Keywords}

Marathon Running, Sudden Cardiac Death, Atherothrombosis, Pre-Race Aspirin Usage 
Sudden cardiac death is the most tragic event during sports and reducing such events is the number one priority in preventive cardiology [1]. While the cardiovascular risk of long distance running is acknowledged as low, the marathon has come to be regarded by many as the gold standard for achieving ideal heart health in spite of the disturbing legacy of Pheidippides in 490 B.C. (Figure 1) [2]. Epidemiological studies generated by concern over the persistent occurrence of race-related fatalities now provide robust evidence upon which to evaluate these acute cardiac risks.

A 10-year prospective registry of long distance road races in the United States beginning in the year 2000 showed the overall incidence of cardiac arrest and sudden death to be 1 in 184,000 and 1 in 259,000 runners, respectively, which was interpreted by the authors as lower than expected and thereby good news for runners [3] [4]. Male gender and the full marathon compared to half-marathon were significant risk factors among 59 cardiac arrests in runners with an average age of 42 years, which events also increased 2.3-fold in middle-aged males since the year 2005. While the overall rate of cardiac arrest was 1 in 57,000 runners since 1980 in United States marathons by retrospective reporting from race medical directors, such events increased in males over age 29 from 1 in 29,000 to 1 in 22,000 since the year 2000 [5] [6].

Atherosclerotic heart disease was the main cause of marathon-related sudden cardiac death in middle-aged males in two retrospective studies including the report of acute myocardial infarction in 17 of 18 cases in those over 45 years of age [7]. The increasing frequency of such race-related acute cardiac events in runners whose metrics for cardiovascular risk fall below the threshold for primary aspirin prophylaxis by current subspecialty guidelines is unexpected, especially given a concurrent decline in cardiac mortality rates in the general population [8].

An explanation for these counter-intuitive findings may emerge from observations on asymptomatic middleaged male physician-runners who provided pre- and post-race blood samples at sequential Boston marathons beginning in the 1980s as attendees at pre-race scientific symposia of the American Medical Athletic Association

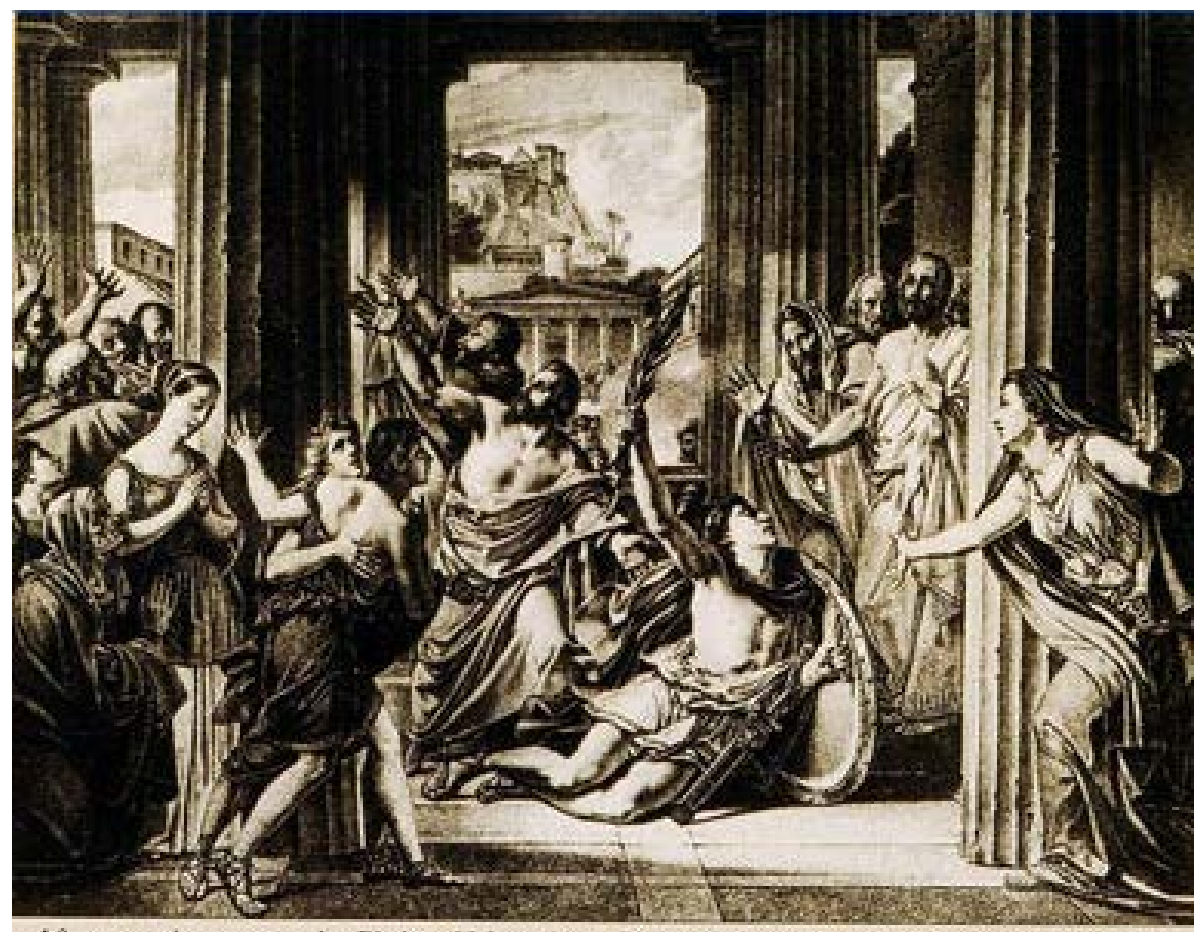

After running across the Plain of Marathon. Phidiopides delivered his messare and died.

Figure 1. Pheidippides' sudden cardiac death in the Atheneum in 490 B.C. after declaring victory over the invading Persian army on the Plains of Marathon (by anonymous). Unforseeing one! Yes, he fought on Marathon day: So, when Persia was dust, all cried "To Akropolis! Run, Pheidippides, one race more. Till in Athens he broke, 'Rejoice, we conquer!'” Joy in his blood bursting his heart, he died — the bliss! "Pheidippides" by Robert Browning, 1879. 
Elevated post-race creatine kinase as an index of rhabdomyolysis after "hitting the wall” was accompanied by a polymorphonuclear leukocytosis with sequential increases in interleukin(IL)-6 and C-reactive protein [9]-[11]. Elevations in these inflammatory biomarkers, which predict acute cardiac events in healthy persons, were accompanied by increased fibrinogen, von Willebrand factor and D-dimer with in vivo platelet activation, indicating a concurrent hemostatic imbalance with pro-coagulant effects [12] [13]. Cardiac biomarkers including cardiac troponins I and T and NT-pro-B-type natriuretic peptide were transiently increased after races in these same asymptomatic runners [14]-[16].

Asymptomatic middle-aged male physician-runners morph from low to high short-term risk for acute cardiac events during races as shown by the profile of biomarkers similar to those which occur in patients with acute coronary syndromes [17]. Inflammatory mediators such as IL-6 have been directly implicated in promoting rupture of previously silent non-obstructive coronary plaques and leakage of cardiac biomarkers to be predictive of thrombotic events in primary prevention studies [18]-[21]. The report of acute myocardial infarction due to coronary thrombosis with plaque rupture in 3 runners immediately after the 2011 Boston marathon is the "smoking gun” regarding the pathophysiological relevance of elevated biomarker findings in asymptomatic runners [22]. The increasing cardiac morbidity and mortality associated with marathon running in middle-aged males is due mainly to type 1 myocardial infarction similar to the cause of exertional sudden deaths in same-aged participants in other sports and first responders such as on-duty firemen and police officers [23]-[27].

Similar to the systemic effects of rhabdomyolysis after "hitting the wall” during marathons, inflammation related to severe infections such as community-acquired bacteremia and scrub typhus confer an increased shortterm risk for acute cardiac events [28] [29]. Aspirin usage has been demonstrated to be cardio-protective in conditions such as sepsis and preeclampsia, leading to proposed usage for mitigating high short-term risk in runners as in patients with severe infections [30]-[35]. A single pre-race low-dose aspirin would confer antithrombotic protection during and for the 24 hours after a race even if taken at the starting line so long as it is not enteric coated [36]. Pre-race usage provides runners with the only medication receiving a grade 1A recommendation for pre-hospital treatment of an acute coronary syndrome while minimizing the opportunity for complications such as gastrointestinal bleeding with continuous usage [37].

Responsibility rightly falls upon the marathon medicine community to disclose the transiently increased risk for cardiac arrest in middle-aged males during marathons analogous to the United States Food and Drug Administration's urgent advisory on excess sudden cardiac death based on one case per 1.2 million prescriptions for short-course azithromycin [38] [39]. Pre-race aspirin usage was first recommended for males over age 40 only after approval by their physicians at the 2014 Rio de Janeiro marathon, following an advisory from the International Marathon Medical Directors Association (IMMDA) [40] [41]. Cardiac arrests nevertheless occurred in male runners at the finish line in the last two Rio marathons including coronary stent placements for severe coronary artery disease after successful resuscitation from cardiac arrest in 2015 (personal communication, Paulo Afonso Lourega de Menezes, M.D., medical director) (Figure 2).

Pre-race aspirin usage rightly qualifies as prudent to offset the high, if transient, cardiac risk during marathons based on conclusive evidence for its prevention of first myocardial infarctions in healthy same-aged male non-running physicians in a randomized controlled primary prevention trial [42]. Aspirin has additionally been reported as efficacious for short-term cardio-protection in other clinical conditions which confer inflammatory stress. Pre-race aspirin may be viewed as concordant with current guidelines of the American Heart Association (AHA) and the European Society of Cardiology, which endorse such usage for primary prevention in high-risk subgroups based on appropriate risk stratification [43] [44]. Middle-aged males who fall below the risk threshold for continuous aspirin prophylaxis at baseline by current subspecialty guidelines qualify for limited treatment during marathons by risk stratification of validated biomarkers.

Middle-aged males may transition from beneficial effects on the myocardium during recreational marathon training into high short-term risk for acute coronary events during races [45]. In contrast to mainly non-preventable causes of sudden cardiac death in younger athletes [46] [47], substantial evidence reviewed above supports the case for aspirin as protective against race-related fatalities in susceptible males. Hard data to establish efficacy might emerge from ongoing epidemiological studies following wider acceptance of pre-race aspirin usage as reaffirmed by IMMDA on behalf of marathon medical directors on four continents in response to ongoing cases [48].

A worst-case scenario would be a continued increase in the rate of cardiac arrest related to ever growing participation among middle-aged males many of whom may run marathons under the misapprehension that this 


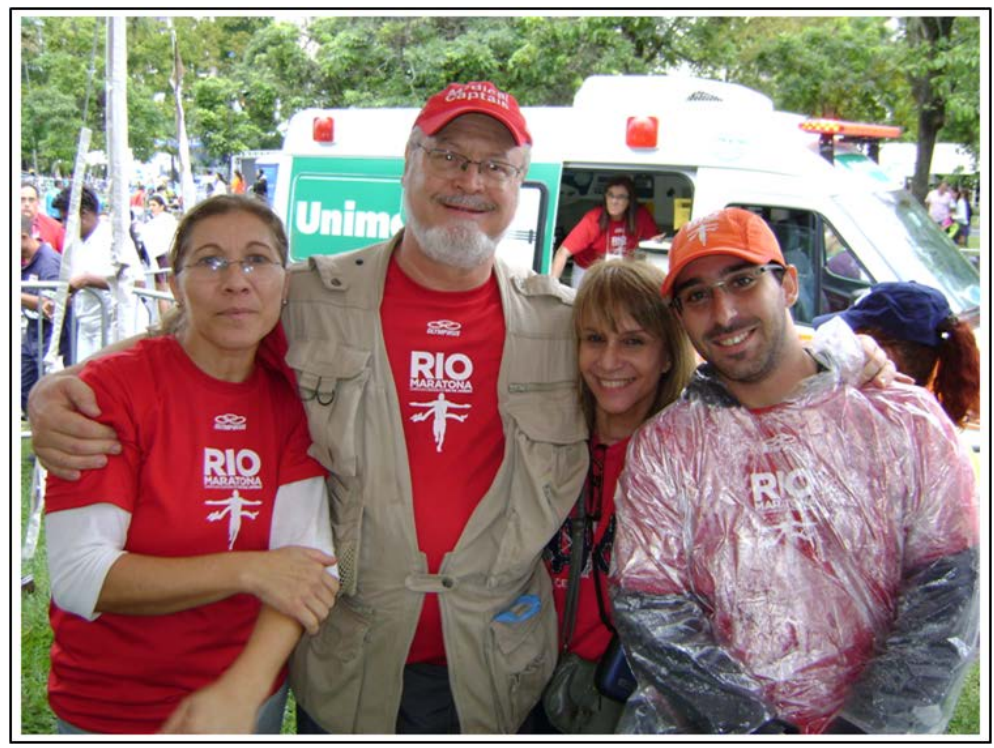

Figure 2. Paulo Afonso Lourega de Menezes, M.D., medical director of the Rio de Janiero marathon, with his team at the finish line medical tent. Male runners in cardiac arrest were successfully resuscitated at the finish line of the 2014 and 2015 in spite of their recommendation that males over age 40 take pre-race aspirin only after approval by their personal physicians.

activity intrinsically promotes optimal cardiovascular health. Prospective studies using the registry model would determine the impact of wider acceptance of pre-race aspirin recommended to susceptible participants. A statistically significant decrease in events over time would solidify the standing of such usage without needing a randomized controlled clinical trial specifically in susceptible runners. Demonstration of a greater than 30\% reduction in cardiac morbidity and mortality with low-dose aspirin in preeclampsia by a systematic literature review demonstrates the potential for applying new clinical findings to current standards of care [31].

Measurement of coronary artery calcium density may be useful for assessing the utility of pre-race aspirin especially for more experienced runners among whom such scores are paradoxically higher compared to matched non-running controls and inversely related to short-term event-free survival [49]-[52]. Disclosure of his personal diagnosis of coronary heart disease by Dave McGillivray, race director of the Boston marathon since 1988, appropriately conveyed the message that even accomplished marathoners are subject to the development of symptomatic coronary atherosclerosis [53]. With 1322 runners at the most common age of 46 years among the 35,384 entrants in the 2014 Boston marathon and 50\% of all runners over the age of 40, disclosure of these cardiovascular concerns warrants inclusion in "cardiac wellness" for runners in official website of the Boston Athletic Association [54] [55].

Reducing excess race-related cardiac morbidity and mortality in susceptible middle-aged males is an ambitious but realistic goal based on the success of the marathon medical community in curtailing fatalities due to exercise-associated hyponatremic encephalopathy since the year 2000 mainly in young females through a robust consensus process [56]-[58]. The health of marathon runners and perhaps the future of the sport may depend on it [59] [60].

\section{References}

[1] Lawless, C.E., Asplund, C., Asif, I.M., et al. (2014) Protecting the Heart of the American Athlete. Proceedings of the American College of Cardiology Sports and Exercise Think Tank, October 18, 2012, Washington, DC. Journal of the American College of Cardiology, 64, 2146-2171. http://dx.doi.org/10.1016/j.jacc.2014.08.027

[2] Bassler, T.J. (1977) Marathon Running and Immunity to Atherosclerosis. In: Milvy, P., Ed., The Marathon; Physiological, Epidemiological and Psychological Studies. Annals of the New York Academy of Sciences, 301, 579-592. http://dx.doi.org/10.1111/j.1749-6632.1977.tb38231.x

[3] Kim, J.H., Malhotra, R., Chiampas, G., et al. for the RACER Study Group (2012) Cardiac Arrest during Long-Distance 
Running Races. New England Journal of Medicine, 36, 130-142. http://dx.doi.org/10.1056/NEJMoa1106468

[4] Nearman, S. (2012) Cardiac Deaths in Marathons Much Lower than Previously Thought: Good News for Marathon Runners. American Medical Athletic Association Journal, 7-8.

[5] Roberts, W.O., Roberts, D.M. and Lunos, S. (2013) Marathon Related Cardiac Arrest Differences in Men and Women. British Journal of Sports Medicine, 47, 168-171. http://dx.doi.org/10.1136/bjsports-2012-091119

[6] Webner, D., Duprey, K.M., Dresner, J.A., et al. (2012) Sudden Cardiac Arrest and Death in United States Marathons. Medicine \& Science in Sports \& Exercise, 1843-1845. http://dx.doi.org/10.1249/MSS.0b013e318258b59a

[7] Mathews, S.C., Narotsky, D.L., Berbholt, D.L., et al. (2012) Mortality among Marathon Runners in the United States, 2000-2009. American Journal of Sports Medicine, 40, 1495-1500. http://dx.doi.org/10.1177/0363546512444555

[8] Go, A.S., Mozaffarian, D., Roger, V.L., et al. (2013) Heart Disease and Stroke Statistics_2014 Update: A Report from the American Heart Association. Circulation. http://circ.ahajournals.org

[9] Siegel, A.J., Silverman, L.M. and Lopez, M.S. (1980) Creatine Kinase Elevations in Marathon Runners: Relationship to Training and Competition. Yale Journal of Biology and Medicine, 53, 275-279.

[10] Kratz, A., Lewandrowski, K.B., Siegel, A.J., et al. (2002) Effect of Marathon Running on Hematological and Biochemical Laboratory Parameters including Cardiac Markers. American Journal of Clinical Pathology, 118, 856-863. http://dx.doi.org/10.1309/14TY-2TDJ-1X0Y-1V6V

[11] Siegel, A.J., Verbalis, J.G., Clement, S., Mendelson, J.H., Mello, N.K., Adner, M., et al. (2007) Hyponatremia in Marathon Runners Due to Inappropriate Arginine Vasopressin Secretion. The American Journal of Medicine, 120, 461.e11-461.e17. http://dx.doi.org/10.1016/j.amjmed.2006.10.027

[12] Siegel, A.J., Stec, J.J., Lipinska, I., Van Cott, E.M., Lewandrowski, K.B., Ridker, P.M., et al. (2001) Effect of Marathon Running on Inflammatory and Hemostatic Markers. The American Journal of Cardiology, 88, 918-920. http://dx.doi.org/10.1016/S0002-9149(01)01909-9

[13] Kratz, A., Wood, M.J., Siegel, A.J., Hiers, J.R. and Van Cott, E.M. (2006) Effects of Marathon Running on Platelet Activation Markers: Direct Evidence for in Vivo Platelet Activation. American Journal of Clinical Pathology, 125, 296-300. http://dx.doi.org/10.1309/PRF5N7P2XM6E243H

[14] Saenz, A.J., Lee-Lewandrowsi, E., Wood, M.J., Neilan, T.G., Siegel, A.J., Januzzi, J.L., et al. (2006) Measurement of a Plasma Stroke Biomarker Panel and Cardiac Troponin T in Marathon Runners before and after the 2005 Boston Marathon. American Journal of Clinical Pathology, 126, 185-189. http://dx.doi.org/10.1309/D7QUF0HJMCYYYY5A

[15] Neilan, T.G., Januzzi, J.L., Lee-Lewandrowski, E., Ton-Nu, T.-T., Yoerger, D.M., Jassal, D.S., et al. (2006) Myocardial Injury and Ventricular Dysfunction Related to Training Adequacy among Non-Competitive Participants in the Boston Marathon. Circulation, 114, 2325-2333. http://dx.doi.org/10.1161/CIRCULATIONAHA.106.647461

[16] Siegel, A.J., Januzzi, J., Sluss, P., Lee-Lewandrowski, E., Wood, M., Shirey, T., et al. (2008) Cardiac Biomarkers, Electrolytes and Other Anylates in Collapsed Marathon Runnners: Implications for the Evaluation of Runners Following Competition. American Journal of Clinical Pathology, 129, 948-951. http://dx.doi.org/10.1309/4L0M60MGAQBCHMV7

[17] Libby, P. and Crea, F. (2010) Clinical Implications of Inflammation for Cardiovascular Primary Prevention. European Heart Journal, 31, 777-783. http://dx.doi.org/10.1093/eurheartj/ehq022

[18] Mauri, L. (2013) Non-Culprit Lesions-Innocent or Guilty by Association. New England Journal of Medicine, 369, 1166-1167. http://dx.doi.org/10.1056/NEJMe1309383

[19] Anderson, D.R., Poterucha, J.T., Mikuls, T.R., Duryee, M.J., Garvin, R.P., Klassen, L.W., et al. (2013) IL-6 and Its Receptors in Coronary Artery Disease and Acute Myocardial Infarction. Cytokine, 62, 395-400. http://dx.doi.org/10.1016/j.cyto.2013.03.020

[20] Lee, T., Murai, T., Yonetsu, T., Suzuki, A., Hishikari, K., Kanaji, Y., et al. (2015) Relationship between Subclinical Cardiac Troponin I Elevations and Culrpit Lesion Characteristics Assessed by Optical Coherence Tomography in Patients Undergoing Elective Percutaneous Coronary Intervention. Circulation: Cardiovascular Interventions, 8, e0011727. http://dx.doi.org/10.1161/CIRCINTERVENTIONS.114.001727

[21] Everett, B.M., Zeller, T., Glynn, R.J., Ridker, P.M. and Blankenberg, S. (2015) High Sensitivity Cardiac Troponin I and B-Type Natriuretic Peptide as Predicators of Vascular Events in Primary Prevention. Circulation, 131, 1851-1860. http://dx.doi.org/10.1161/CIRCULATIONAHA.114.014522

[22] Albano, A.J., Thompson, P.D. and Kapur, N.K. (2012) Acute Coronary Thrombosis in Boston Marathon Runners. New England Journal of Medicine, 366, 184-185. http://dx.doi.org/10.1056/NEJMc1111015

[23] Thygesen, K., Alpert, J.S., Jaffe, A.S., Simoons, M.L., Chaitman, B.R., White, H.D., et al. (2012) Third Universal Definition of Myocardial Infarction. Circulation, 126, 2020-2035. http://dx.doi.org/10.1161/CIR.0b013e31826e1058

[24] Albert, C.M., Mittleman, M.A., Chae, C.U., Lee, I.-M., Hennekens, C.H. and Manson, J.E. (2000) Triggering of Sud- 
den Death from Cardiac Causes by Vigorous Exertion. New England Journal of Medicine, 343, 1355-1366. http://dx.doi.org/10.1056/NEJM200011093431902

[25] Marijon, E., Uy-Evanado, A., Reiner, K., Teodorescu, C., Narayanan, K., Jouven, X., et al. (2015) Sudden Cardiac Arrest during Sports in Middle Age. Circulation, 131, 1384-1391. http://dx.doi.org/10.1161/CIRCULATIONAHA.114.011988

[26] Kales, S.N., Soteriades, E.S., Christophi, C.A. and Christiani, D.C. (2007) Emergency Duties and Deaths from Heart Disease among Firefighters in the United States. New England Journal of Medicine, 356, 1207-1215. http://dx.doi.org/10.1056/NEJMoa060357

[27] Varvarigou, V., Farioli, A., Korre, M., Sato, S., Dahabreh, I.J. and Kales, S.N. (2014) Law Enforcement Duties and Sudden Cardiac Death among Police Officers in the United States: Case Distribution Study. BMJ, 349, g6534. http://dx.doi.org/10.1136/bmj.g6534

[28] Dalager-Pedersen, M., Sogaard, M., Schonheyder, H.C., Nielsen, H. and Thomsen, R.W. (2014) Risk for Myocardial Infarction and Stroke after Community-Acquired Bacteremia: A 20-Year Population-Based Cohort Study. Circulation, 129, 1387-1396.

[29] Chung, W.S., Lin, C.L., Hsu, W.H. and Kao, C.-H. (2014) Scrub Typhus Increases the Risk of Developing Acute Coronary Syndrome: A Nationwide Cohort Study. Heart, 100, 1844-1850. http://dx.doi.org/10.1136/heartjnl-2014-306181

[30] Eisen, D.P., Reid, D. and McBryde, E.S. (2012) Acetyl Salicylic Acid Usage and Mortality in Critically Ill Patients with the Systemic Inflammatory Response Syndrome and Sepsis. Critical Care Medicine, 40, 1761-1767. http://dx.doi.org/10.1097/CCM.0b013e318246b9df

[31] Henderson, J.T., Whitlock, E.P., O’Conner, E., Senger, C.A., Thompson, J.H. and Rowland, M.G. (2014) Low-Dose Aspirin for Prevention of Morbidity and Mortality from Preeclampsia: A Systematic Evidence Review for the U.S. Preventive Service Task the Force. Annals of Internal Medicine, 160, 695-703. http://dx.doi.org/10.7326/M13-2844

[32] Siegel, A.J. (2015) Pre-Race Aspirin Usage to Prevent Cardiac Arrest in Susceptible Runners during Marathons: Is Opportunity Knocking? Open Heart, 2, e000102.

[33] Siegel, A.J. (2012) Pheidippides Redux: Reducing Acute Cardiac Risk during Marathon Running. The American Journal of Medicine, 125, 630-635. http://dx.doi.org/10.1016/j.amjmed.2011.11.008

[34] Siegel, A.J. (2013) Aspirin Usage Pre-Race to Prevent Cardiac Arrest in Marathon Runners during Races. The American Journal of Medicine, 126, e47. http://dx.doi.org/10.1016/j.amjmed.2013.06.024

[35] Walkey, A.J. (2014) Preventing Cardiovascular Complications of Acute Infection: A Missed Opportunity? Circulation, 129, 1375-1377. http://dx.doi.org/10.1161/CIRCULATIONAHA.114.008712

[36] Grosser, T., Fries, S., Lawson, J.A., Kapoor, S.C., Grant, G.R. and FitzGerald, G.A. (2013) Drug Resistance and Pseudo-Resistance: An Unintended Consequence of Enteric-Coated Aspirin. Circulation, 127, 377-385. http://dx.doi.org/10.1161/CIRCULATIONAHA.112.117283

[37] Cohen, S.I. and Ellis, E.R. (2012) Death and Near Death from Cardiac Arrest during the Boston Marathon. Pacing and Clinical Electrophysiology, 35, 241-244. http://dx.doi.org/10.1111/j.1540-8159.2011.03248.x

[38] Ray, W.A., Murray, K.T., Hall, K., Arbogast, P.G. and Stein, C.M. (2012) Azithromycin and Risk of Cardiovascular Death. New England Journal of Medicine, 366, 1881-1890. http://dx.doi.org/10.1056/NEJMoa1003833

[39] Azithromycin Poses Fatal Cardiac Risk. FDA Warns. http://www.fda.gov/Drugs/DrugSafety/ucm304372.htm

[40] Maharam, L.G., Siegel, A.J., Siegel, S., Adams, B., Pujol, P. and de Menezes, P.A.L. (2010) IMMDA’s Health Recommendations for Runners \& Walkers. Approved by the International Marathon Medical Directors Association (IMMDA), Barcelona, 20 March 2010. http://www.IMMDA.org

[41] Lourega de Menezes, P.A. (2014) Official Handbook for Runners in the Rio de Janeiro Marathon. Marathon Publications, 12-13.

[42] Steering Committee of the Physicians' Health Study Research Group (1989) Final Report on the Aspirin Component of the Ongoing Physicians’ Health Study. New England Journal of Medicine, 321, 129-135. http://dx.doi.org/10.1056/NEJM198907203210301

[43] Pignone, M., Alberts, M.J., Colwell, J.A., Cushman, M., Inzucchi, S.E., Mukherjee, D., et al. (2010) Aspirin for Primary Prevention of Cardiovascular Events in People with Diabetes. Journal of the American College of Cardiology, 55, 2878-2885. http://dx.doi.org/10.1016/j.jacc.2010.04.003

[44] Halvorsen, S., Andreotti, F., Berg, J.M., Cattaneo, M., Coccheri, S., Marchioli, R., et al. (2014) Aspirin Therapy in Primary Cardiovascular Disease Prevention. A Position Paper of the European Society of Cardiology Working Group on Thrombosis. Journal of the American College of Cardiology, 64, 319-327.

http://dx.doi.org/10.1016/j.jacc.2014.03.049 
[45] Zilinski, J.L., Contursi, M.E., Isaacs, S.K., Deluca, J.R., Lewis, G.D., Weiner, R.B., et al. (2015) Myocardial Adaptations to Recreational Marathon Training among Middle-Aged Men. Circulation: Cardiovascular Imaging, 8, e002487. http://dx.doi.org/10.1161/circimaging.114.002487

[46] Harmon, K.G., Drezner, J.A., Wilson, M.G. and Sharma, S. (2014) Incidence of Sudden Cardiac Death in Athletes: A State of the Art Review. British Journal of Sports Medicine, 48, 1185-1192. http://dx.doi.org/10.1136/bjsports-2014-093872

[47] Maron, B.J., Haas, T.S., Murphy, C.J., Ahluwalia, A. and Rutten-Ramos, S. (2014) Incidence and Causes of Sudden Death in U.S. Athletes. Journal of the American College of Cardiology, 63, 1636-1643. http://dx.doi.org/10.1016/j.jacc.2014.01.041

[48] Siegel, A.J. (2015) IMMDA Advisory, 2015: Pre-Race Aspirin to Prevent Heart Attack and/or Cardiac Arrest during Long Distance Running. http://www.IMMDA.org

[49] Miedema, M.D., Duprez, D.A., Misialek, J.R., Blaha, M.J., Nasir, K., Silverman, M.G., et al. (2014) Use of Coronary Artery Calcium Testing to Guide Aspirin Utilization for Primary Prevention: Estimates from the Multi-Ethnic Study of Atherosclerosis. Circulation. Cardiovascular Quality and Outcomes, 7, 453-460. http://www.ncbi.nlm.nih.gov/pubmed/24803472

[50] Mohlenkamp, S., Lehmann, N., Breuckmann, F., Brocker-Preuss, M., Nassenstein, K., Halle, M., et al. (2008) Running and the Risk of Cardiac Events: Prevalence and Prognostic Relevance of Coronary Atherosclerosis in Marathon Runners. European Heart Journal, 29, 1903-1910. http://dx.doi.org/10.1093/eurheartj/ehn163

[51] Schwartz, R.S., Kraus, S.M., Schwartz, J.G., Wickstrom, K.K., Peichel, G., Garberich, R.F., et al. (2014) Increased Coronary Artery Plaque Volume among Male Marathon Runners. Missouri Medicine, 111, 85-90.

[52] Mohlenkamp, S., Leineweber, K., Lehmann, N., Braun, S., Roggenbuck, U., Perrey, M., et al. (2014) Coronary Atherosclerosis Burden, but Not Transient Troponin Elevation, Predicts Long-Term Outcome in Recreational Marathon Runners. Basic Research in Cardiology, 109, 391-395. http://dx.doi.org/10.1007/s00395-013-0391-8

[53] Buckley, S. (2013) Dave McGillivray Fights Heart Disease. Boston Herald, 24 December 2013. http://running.competitor.com/2013/12/news/boston-marathon-rd-dave-mcgillivray-fights-heart-disease 91871

[54] Knox, L. and Estaban, C. (2014) In the Running, Marathon Demographics. Boston Globe. C 8-9, 18 April 2014.

[55] D’Hemecourt, P.A., Dyer, K.S. and Baggish, A.L. Cardiac Wellness. Boston Athletic Association. Accessed 19 April 2015. http://www.baa.org

[56] Siegel, A.J. (2015) Fatal Water Intoxication and Cardiac Arrest in Runners during Marathons: Prevention and Treatment Based on Validated Clinical Paradigms. The American Journal of Medicine. (in press) http://dx.doi.org/10.1016/j.amjmed.2015.03.031

[57] Hew-Butler, T., Rosner, M.H., Fowkes-Godek, S., Dugas, J.P., Hoffman, M.D., Lewis, D.P., et al. (2015) Statement of the 3rd International Exercise-Associated Hyponatremia Consensus Development Conference, Carlsbad, California, 2015. Clinical Journal of Sport Medicine, 25, 303-320. http://dx.doi.org/10.1097/JSM.0000000000000221

[58] Rosner, M.H. Preventing Deaths Due to Exercise-Associated Hyponatremia: The 2015 Consensus Guidelines. Clinical Journal of Sports Medicine, 25, 301-302.

[59] Yared, K. and Wood, M.J. (2009) Is Marathon Running Hazardous to Your Cardiovascular Health? The Jury Is Still Out. Radiology, 251, 3-5. http://dx.doi.org/10.1148/radiol.2511090041

[60] Noakes, T. (2014) Time to Quit That Marathon Running? Not Quite Yet! Basic Research in Cardiology, 109, $395-396$. http://dx.doi.org/10.1007/s00395-013-0395-4 